\title{
Suggestions for Developing "Alumni Economy" Based on Organizational Management Method
}

\author{
Huang Haoxiang \\ Alumni Relations Department, Xi'an Jiaotong University, Xi'an 710000, China
}

Keywords: Alumni economy; Alumni association; Local economy.

\begin{abstract}
Since 2017, the "Million Alumni Intelligence Back to Han Project" in Wuhan has successfully activated the alumni economy, and then Xi'an, Nanjing and other cities have paid great importance to the alumni economy. As a new economic form, the alumni economy will become a new key to urban economic development. Starting from the actual cases, combining the relevant theories of economics, a research of promoting the economic development of alumni is analyzed with the method of causal analysis diagram in management science, and practical thinking and suggestions are put forward. It is expected to provide references for local governments, universities, alumni associations and other multi-party organizations to enhance the actual effect of alumni economy development.
\end{abstract}

\section{Introduction}

In 1997, economist Lv Shijie first put forward the concept of "alumni economy". However, in the 20 years after the concept was put forward, the society did not pay attention to it. Until 2017, Wuhan took the lead in launching the "Million Alumni Intelligence Back to Han Project " and by the end of 2017, the activity brought about a total investment of 1.3 trillion yuan for Wuhan, more than half of the total investment of Wuhan. The successful activation of alumni economy in Wuhan aroused widespread concern in the society. At the end of 2017, Xi'an launched the "Dream Back to Chang'an - Million Alumni Return" activity, and introduced six measures to support the return of alumni. These measures include providing first-class government services, supporting the establishment of research and development centers, giving priority to ensuring land demand and so on. As of May 2018, "Alumni return to economy" has brought more than 600 billion yuan to Xi'an, which has also attracted wide media attention [5].

As a "new front" city, Xi'an has the fifth largest number of colleges and universities in China, and the second largest number of 985 colleges and universities in the country, nearly 100 colleges and universities of all kinds, 200,000 graduates a year. Rich educational resources are the unique development advantages of the city. To promote the development of the city with the help of alumni economy should become an important link in the layout of urban development.

From the concept of "alumni economy", it can be seen that the alma mater is an important link between alumni and society, and also the core in the development of alumni economy. Alumni work 
will directly affect the exchange between alumni and society, thus affecting the feedback, investment and cooperation of alumni and a series of interactive behaviors. How to boost alumni economy and contribute to urban development through effective alumni work? Based on the theories related to organizational behavior and social psychology, the work related to the development of alumni economy is analyzed.

\section{Three Elements in Alumni Economy}

Alumni association, as a social organization under the leadership of universities, has the organizational structure and corresponding functions to contact alumni, serve alumni and serve their alma mater[1]. At the same time, it is also the most universal and basic alumni organization, and it plays an important role in contacting and communicating with their alma mater, as well as organizing and coordinating alumni activities. The construction and development of alumni association plays an important role in maintaining the feelings of alumni. A good organization of alumni association can effectively promote the interaction between "alumni - alma mater - society" and promote the development of alumni economy[2].

Alumni association, as a social organization, possesses various characteristics of the organization. In organizational behavior, the construction of an organization is defined as "making the existing interaction into a visible sequence, thereby producing meaningful results". In the meanwhile, "an organization is a recognizable social entity, which pursues multiple objectives through the coordinated activities of its members. The roles within the organization are closely linked and share common expectations ". It is the problem that all colleges and universities need to think about in the current alumni work how to make the organizational behavior of alumni association sequential in the process of organizing, not only to meet the multiple objectives of the members of the organization, but also to meet the expectations of the alma mater and the society for such organizations and to enter a healthy development situation.

\section{Goal Decomposition and Variable Analysis in the Alumni Economy Development}

If "promoting the development of alumni economy" is set as the ultimate goal, the task objectives of alumni, alma mater and relevant government departments (social organizations) are decomposed, and the countermeasure causality diagram is drawn, as shown in Figure 1.

Figure 1 shows that, if the ultimate goal is promoting the development of alumni economy, the relevant government departments, alumni workers and alumni associations in colleges need to play a key role and cooperate closely. Government departments should focus on creating brand activities related to alumni economy, such as alumni centralized returning to investment and centralized project inspection [3]. Government departments should also publicize and promote the activities. On the basis of fixing the content, process and frequency of brand activities, expanding the depth and breadth of activities, more colleges and alumni can participate in them. On the other hand, the government should also introduce relevant policies to support the development of education in colleges and optimize the alumni investment.

As a link between alumni and society, alumni workers in colleges and universities, on the one hand, need to continue to play the important role in alumni liaison. On the other hand, they should strengthen communication and cooperation with government departments, create multiple platforms within the scope of alumni economy, help the government to increase and improve the entry point of alumni economy, and also lay a good foundation for their own industry-university-research cooperation [4]. 


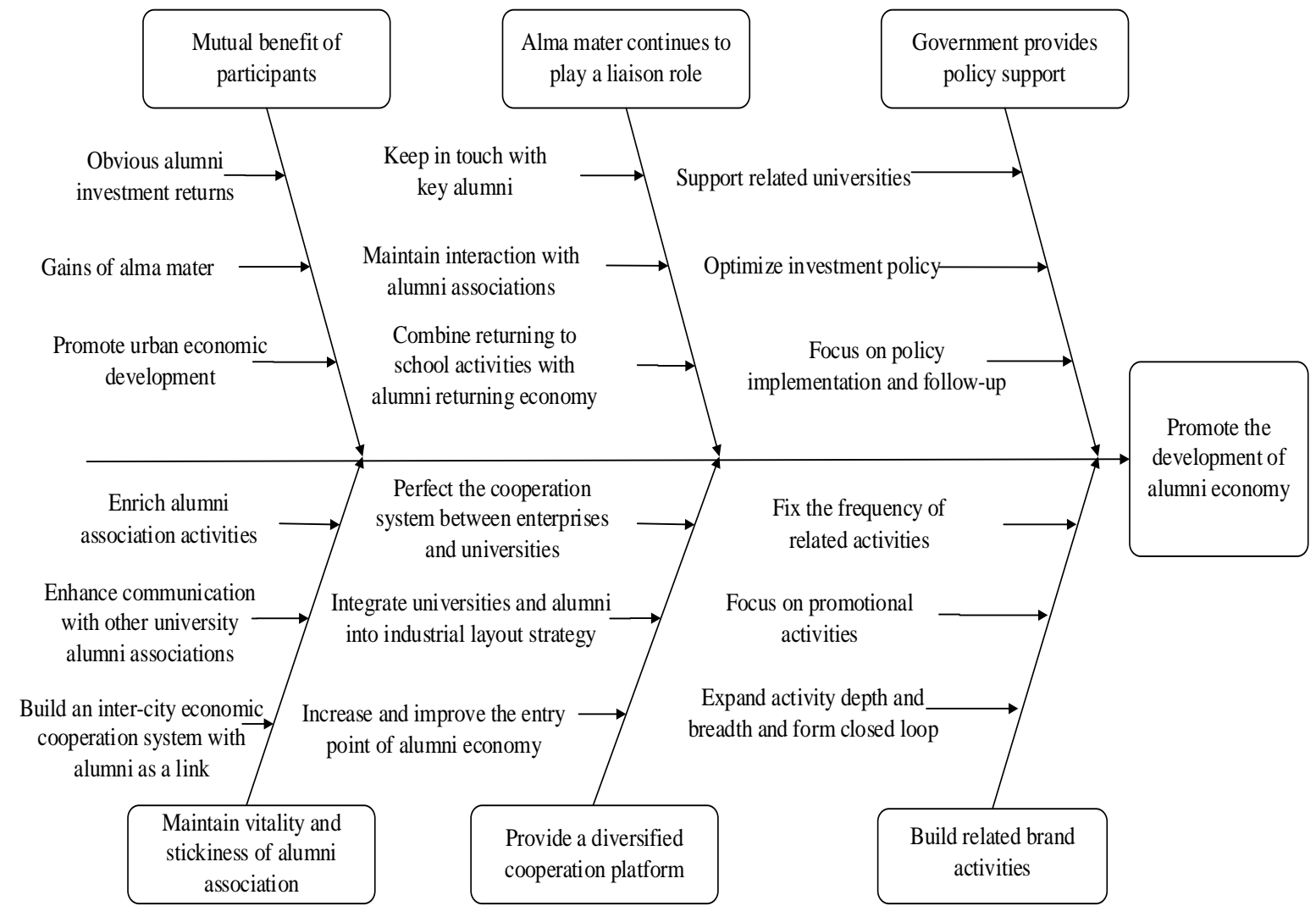

Fig. 1 The countermeasure causality diagram

As a non-governmental organization, alumni association in colleges and universities has its particularities. For example, the administrators of alumni association are all part-time so that they cannot devote themselves to alumni work completely; the members of alumni association have various ages, professions and positions, which make it more difficult to design organizational activities. This requires the alma mater to guide the work of the alumni association, and actively contact and design activities to maintain the vitality of the organization of the alumni association.

According to the current actual situation, there are still many problems in the related work of alumni economy. For instance, the related activities organized by the government are mostly mere formalities, cannot be effectively followed up and implemented. And there is a phenomenon of multi-management in the organization and management, resulting in inefficient work and duplication. After all, the alumni economy, as a new one economic form, requires continuous progress and reform for all participants. Moreover, alumni work in domestic universities has not been carried out for a long time, and has not been given sufficient attention and input. Both alumni activity organization and the frequency of alumni contacts cannot be compared with the work of alumni in well-known universities in Europe and the United States [6]. The construction mechanism of alumni association is not perfect enough, which will become an obstacle to the development of alumni economy.

The direct effect of alumni association on the development of alumni economy is analyzed by drawing a causal loop diagram, extracting the quantifiable variables in Figure 1, and introducing two variables, namely, the scale of alumni association and the regional economic level of the city where the alumni are located. Then, Figure 2 can be obtained. 


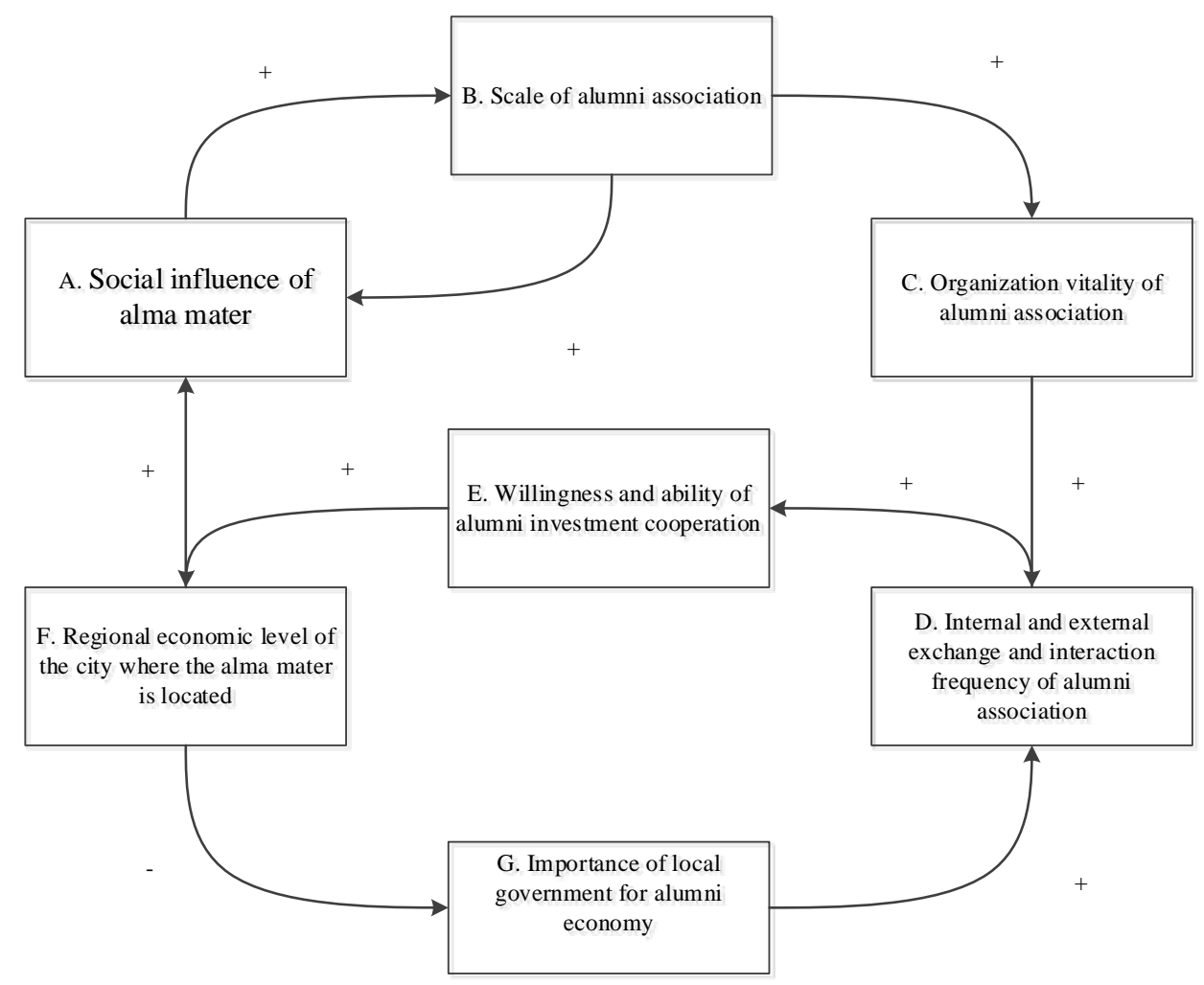

Fig. 2 Closed causal loop

Firstly, the reasons for introducing the two variables of "alumni association scale" and "the regional economic level of the city where the alma mater is located" are briefly expounded. A university will have many alumni associations all over the country and even around the world, but the scale of each alumni association varies greatly, which is closely related to the urban volume and economic level of the city. Large-scale developed cities are more attractive to employment, which determines the number and level of talents. Alumni associations in large cities have a larger organizational scale, more alumni and a wider range of industries and occupations [7]. Therefore, alumni associations in large developed cities are often the focus of alumni work.

The regional economic level of the city where the alma mater is located determines the demand for the alumni economy. At the same time, it will also have a certain impact on the quantity and quality of university enrollment in the city, thus directly affecting the personal development of alumni in the future. Regional economic level also determines the breadth and depth of regional industrial layout, which is also an important factor in establishing cooperation with alumni in the future.

Figure 2 clearly illustrates the interaction of the seven variables. The "+" (plus sign) beside the arrow indicates that the two associated variables change in the same direction. Taking the scale of alumni associations as an example, after the scale of alumni association increases, its organizational vitality will also be improved. The reason is that there will be more organizational internal interaction and more organizational behaviors will be stimulated after the members of the organization become more. At the same time, when the scale of alumni association expands, its activity scale is also expanded, which can enhance their social influence and indirectly improve the social reputation of the alma mater. And when the social influence of the alma mater is improved, more alumni will be attracted to join the alumni associations and thus expand the scale of the alumni association.

A-B-C-D-E-F-A in Figure 2 has formed a closed causal loop, but the situation is not as optimistic as it might have been expected. The reason is that the loop is purely positive, and after each cycle, all variables are amplified once. Whereas, in the causal loop without negative correlation (i.e., the minus 
sign in the loop is zero or even number), there is no adjustment or control. Once a variable deviates, the variable will continue to move in this direction, which may lead to a vicious cycle and cannot be corrected [1]. For example, take F in Figure 2 as the starting point, when the regional economic level of the city where the alma mater is located falls sharply due to the change of industrial structure or the deterioration of economic environment, the quality and quantity of college enrollment in the region will be affected. As a result, it will also directly affect the number and level of alumni several years later, resulting in that, in the future, the alumni economy is unlikely to make a great contribution to the "recovery" of local economic level.

Therefore, it is necessary to introduce a "negative correlation" variable into the causal loop to control the deviation accordingly, so that the whole organizational system is stable. The variable G "the importance of local government for alumni economy" is selected. Firstly, the variable itself can be controlled by government actions. Secondly, the variable does not mean that when the economic level of a city reaches a certain level, the government and the alma mater can relax the work of alumni and reduce the interaction with alumni associations. It means that, when the city's economic level reaches a certain level, it should not rely on the contribution of alumni economy, but look for ways and means of attracting investment with higher efficiency and larger volume. At this time, the government and universities should also maintain close contact with the alumni associations, but the interactive way can be more inclined to pure emotional maintenance and communication, such as alumni sports club competitions, alumni group tours and other activities held frequently by famous alumni associations in Europe and America. When the process of regional economic development requires the cohesion of alumni in colleges and universities to make feedback, a good emotional foundation is still a strong guarantee for alumni to help local economic development.

\section{Suggestions and Conclusion}

According to the relevant analysis in the second chapter, relevant suggestions are put forward on the development of alumni economy, the government departments, universities and alumni associations.

Relevant functional departments of the government:

Local governments should establish contacts with alumni associations through colleges and universities, maintain daily exchanges and interactions, introduce relevant policies to attract foreign investment, create a diversified platform for cooperation, and establish conditions for the development of alumni economy.

Establish a special department of alumni economic work, which is responsible for liaising with the return of alumni and the cooperation of alumni to avoid the disorder and inefficiency caused by multi-management.

On the basis of the full understanding and communication among the government, universities and alumni, and according to the local economic development, industrial layout, strategic planning and other factors, the university takes the lead and the government supports the establishment of professional alumni associations with alumni as the subject. As a result, they can achieve accurate contact in the project cooperation of specific industries.

It is not only the duty of alumni to give back to their alma mater. Local governments should continue to support the development of higher education. The level of education has a direct impact on the development of local economy. Developing education from the root is the main way to promote economic and civilized progress. Establishing a mutual support system of "higher education - alumni - alumni economy" will form a win-win situation for three parts.

Alumni work in universities:

In the process of alumni association construction, the concept of alumni can be appropriately 
expanded. It should not confined to academic education only, but those who have vocational training, on-the-job training and other experience can also be included in the alumni association, so as to achieve the purpose of expanding the scale of the alumni association.

In the process of building alumni associations, colleges and universities should provide targeted guidance and improve the working mechanism of alumni associations, including publicizing the government's policy of attracting investment, and sharing cases of other alumni associations helping the development of alumni economy. In the process of alumni association construction, it is necessary to set up the consciousness of helping the development of alumni economy and establish corresponding working channels and mechanisms.

By utilizing the resource advantages of colleges and universities, combining theory with practice, and setting up special subjects with related disciplines, a continuous analysis of the work related to alumni economy is made, the experience is summed up, and the methods of work are improved.

University alumni association:

Set special person to be responsible for the docking and liaison between the economic cooperation projects and timely exchange of information.

Based on the platform of local alumni associations, establish an alumni organization with industry and industry as its commonness. Starting from internal win-win cooperation, seek opportunities for external cooperation with organizations as its units, establish a fixed cooperation mechanism, and eventually return alumni economy to the alma mater and the local economy of the city where the alma mater is located.

To sum up, the development of alumni economy requires alumni associations, alma maters and local governments to give full play to their respective functions and roles, to build a long-term mechanism, and to form a close community of destiny. It is expected that, alumni economy, as a new economic form, can contribute more and more to the economic development of the region.

\section{References}

[1] XIE, S. W., \& LI, Y. Y. (2017). The Impact of Alumni Relation between Senior Managers and CPAs on Audit Opinions: Evidences from China's Securities Market. Contemporary Finance \& Economics, 6, 011.

[2] Cooper, B., \& Ramey, E. A. (2014). Pluralism at work: Alumni assess an economics education. International Review of Economics Education, 16, 63-72.

[3] Durango-Cohen, E. J., \& Balasubramanian, S. K. (2015). Effective segmentation of university alumni: Mining contribution data with finite-mixture models. Research in Higher Education, 56(1), 78-104.

[4] Barron, J. (2015). Building a chain of success in marketing higher education: The alumni connection. Industrial and Commercial Training, 47(5), 253-256.

[5] Kegao, Y., \& Oulin, L. (2015). Financing Effect of Director Relevance: Investigation into the Relationship Between Col ege Education Foundation and Alumni Association. China Nonprofit Review, 1, 006.

[6] Xingfeng, C. H. E. N. (2015). Probe into the Alumni Service of University Library. Sci-Tech Information Development \& Economy, 10, 044.

[7] Martin, N. D., \& Frenette, A. (2017). Lost in transition: College resources and the unequal early-career trajectories of arts alumni. American Behavioral Scientist, 61(12), 1487-1509. 